\title{
How far are single-chain polymer nanoparticles in solution from the globular state?
}

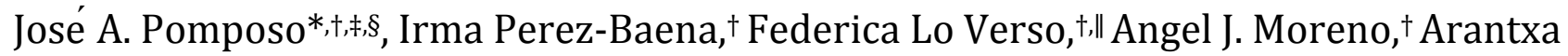 \\ Arbe, ${ }^{\dagger}$ and Juan Colmenero ${ }^{\dagger, \dagger, \|}$ \\ ${ }^{\dagger}$ Centro de Física de Materiales (CSIC, UPV/EHU)-Materials Physics Center, Paseo Manuel de Lardizabal 5, 20018 San \\ Sebastián, Spain \\ ‡ Departamento de Física de Materiales, Universidad del País Vasco (UPV/EHU), Apartado 1072, 20800 San Sebastián, \\ Spain \\ $\S$ IKERBASQUE - Basque Foundation for Science, Alameda Urquijo 36, 48011 Bilbao, Spain
}

\|Donostia International Physics Center (DIPC), Paseo Manuel de Lardizabal 4, 20018 San Sebastián, Spain

Supporting Information

\begin{abstract}
Single-chain nanoparticles (SCNPs) are unimolecular soft nano-objects, consisting of individual polymer chains collapsed to a certain degree by means of intramolecular bonding. Many of the potential applications of SCNPs rely on their particular molecular architecture. Even if the ultimate goal is to produce globular protein-like soft nanoparticles, recent SANS and SAXS results -supported by computer simulations- indicate that SCNPs in solution actually adopt sparse configurations. Herein we compile size data from the literature for a large number of SCNPs in solution, covering from covalent to non-covalent bonded SCNPs, and provide a comparison with the corresponding data for compact or partially swollen globules of the same nature and molar mass. This comparison gives a clear idea of how far from the compact globule limit are current SCNPs. A quantification of the departure from the globular state is provided in terms of size scaling laws. This procedure facilitates a comparison with the size scaling laws observed for folded proteins with globular conformation as well as intrinsically disordered proteins which, on average, exhibit a certain local compaction when compared to chemically denatured proteins. Lastly, the underlying physical mechanism for the noncompact morphology of SCNPs in solution is put forward and guidelines for the potential synthesis of true SCNP globules in solution are suggested.
\end{abstract}

Single-chain technologies are a new paradigm for the development of future soft, smart nanodevices. ${ }^{1}$ Single-chain nanoparticles (SCNPs) can be envisioned as a key element of this innovative field relying in autonomous, individual-polymer devices displaying useful functions. ${ }^{2}$ Current SCNPs are unimolecular soft nano-objects, consisting of individual polymer chains collapsed to a certain degree by means of intramolecular bonding. ${ }^{3,4}$ However, when compared to the million years of evolution leading to sequence-, structure- and functiondefined natural biomacromolecules (e.g., proteins, DNA), our current techniques to control the tertiary, secondary or even primary structure of folded/collapsed individual synthetic polymer chains are still very limited. ${ }^{5}$

Nowadays, SCNPs are synthesized mainly from macromolecular precursors containing reactive functional groups placed in a random manner along the polymer chain. Intrachain crosslinking is often carried out in good solvent at high dilution conditions to avoid unwanted intermolecular coupling events. The ultimate goal is to produce globular protein-like soft nanoparticles. However, very recent scattering experiments by SANS and SAXS, ${ }^{6-8}$ as well as complementary molecular dynamics (MD) simulations, ${ }^{9,10}$ point to a non-compact, nonglobular morphology of SCNPs synthesized with state-of-theart intrachain collapsing techniques in solution. Representative examples are illustrated in Figure 1a-e. Hence, by starting from linear precursors having the typical extended, selfavoiding conformation in good solvent (Fig. 1a), MD simulation results have revealed a sparse morphology of SCNPs in solution (Fig. 1b). ${ }^{9,10}$ Even by using the same precursor, crosslinking initiated from different (statistical) configurations leads to highly polydisperse topologies of the resulting SCNPs. ${ }^{9,10}$ Such morphologies resemble those observed in intrinsically disordered proteins (IDPs) with locally compact portions of the peptide chain connected by flexible segments (Fig. 1c). MD simulation results were found to be in excellent agreement with SANS and SAXS data. ${ }^{6-9}$ As illustrated in Fig. 1d, the Kratky plot for the scattering form factor of SCNPs is qualitatively similar to that of IDPs and rather different from that of compact globular proteins. ${ }^{11}$ Also, even if originally assumed as compact and globular, an elongated structure in solution of non-covalent bonded SCNPs with pendant hydro- 
gen bonding motifs has been recently deduced from SANS measurements (Fig. 1e). ${ }^{12}$

(a)

(d)

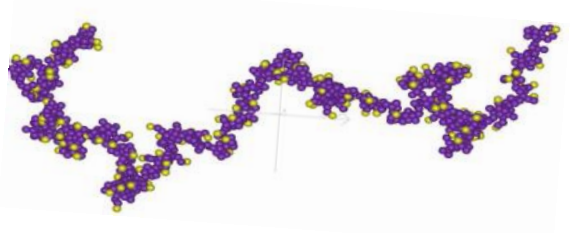

(b)

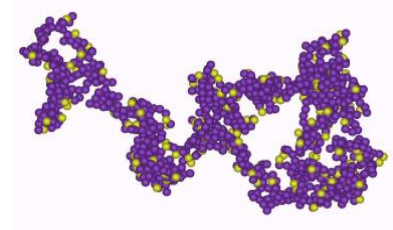

(c)

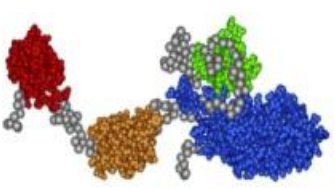

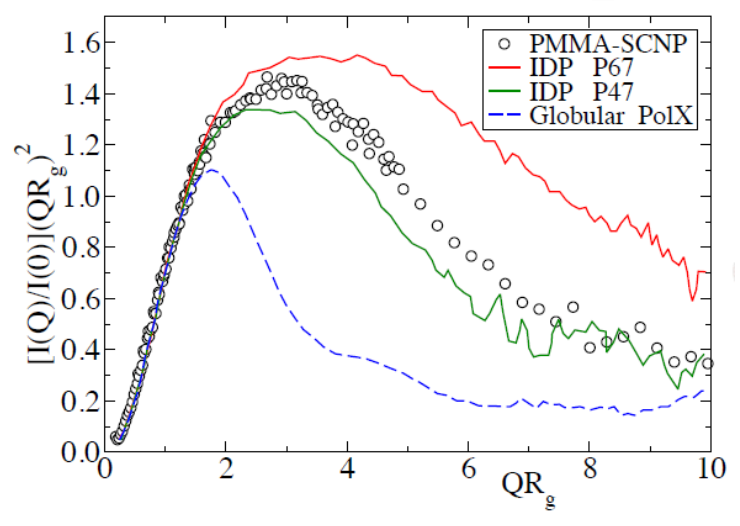

(e)

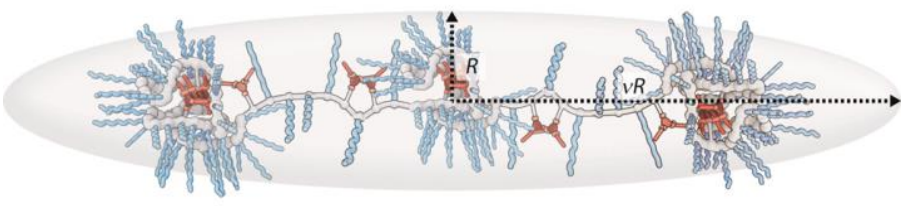

Figure 1. (a) Typical conformation of a SCNP precursor under good solvent conditions from MD simulations. (b) Typical morphology of a SCNP obtained by intrachain cross-linking of the SCNP precursor as revealed by MD simulations. Computer simulations were found to be in excellent agreement with experimental SANS and SAXS data. ${ }^{6-9}$ (c) The SCNP conformation illustrated in (b) resembles that adopted by intrinsically disordered proteins with locally compact portions of the peptide chain connected by flexible segments. Reprinted from ref 6 . Copyright 2013 American Chemical Society. (d) Kratky plot for the form factors of representative PMMA-SCNPs (symbols), compared with that of IDPs (solid lines) ${ }^{11}$ and globular proteins (dashed line). ${ }^{11} I(Q), Q$ and $R_{\mathrm{g}}$ are the scattered intensity, wavevector and radius of gyration, respectively. Data for the SCNPs have been obtained by us. Data for the proteins are sampled from Fig. 2 of ref 11 . (e) Contrary to the initially proposed compact globular morphology in solution, recent analysis of SANS data from SCNPs with pendant hydrogen bonding motifs has revealed the actual elongated shape of these non-covalent bonded nano-objects in water. Reprinted from ref 12 . Copyright 2014 American Chemical Society.

All the above evidences against a compact, globular morphology of SCNPs in solution, aimed us to analyze the size data reported in the literature for a large number of SCNPs in solution covering from covalent and dynamic covalent to noncovalent bonded SCNPs, to investigate if this is a general behavior as suggested by the coarse-grained MD simulation results, and to quantify how far are current SCNPs in solution from the globular state.

Table 1 summarizes hydrodynamic size data for poly(styrene) single-chain nanoparticles (PS-SCNPs) in solution synthesized from 30 different precursors and 11 different cross-linking chemistries, including covalent bonds (CBs), ${ }^{13-21}$ dynamic covalent bonds (DCBs) ${ }^{22}$ and non-covalent bonds (NCBs), ${ }^{23}$ compared to predicted size data for compact and partially swollen PS globules of the same $M_{w}$. Hydrodynamic size of the PS precursor $\left(R_{H}{ }^{\mathrm{SEC}}\right)$ was calculated according to: $R_{H}^{\mathrm{SEC}}(\mathrm{nm})=1.44 \times 10^{-2} M_{w}^{0.561}$, which is the recommended expression $^{24}$ for estimating the hydrodynamic radius of lowdispersity PS chains based on $M_{w}$ data from size exclusion chromatography (SEC) in THF calibrated with PS standards. From the reported apparent weight average molecular weight ${ }^{25}$ from SEC measurements in THF $\left(M_{w}{ }^{a p p}\right)$, the hydrodynamic radius of the SCNPs was obtained as $R_{H}{ }^{\mathrm{SEC}}(\mathrm{nm})=1.44 \times 10^{-2}$
$\left(M_{w}{ }^{a p p}\right)^{0.561}$. Hydrodynamic size data as determined from dynamic light scattering (DLS) measurements in THF $\left(R_{H}{ }^{\text {DLS }}\right)$ are also provided in Table 1, when available, for comparison. Data in which $R_{H}{ }^{\text {DLS }}$ (PS-SCNP) $>R_{H}^{\text {SEC }}$ (PS-Precursor) are indicated in parentheses in Table 1. This inconsistency in some of the reported DLS values might be attributed to an underestimation of the value of $R_{H}^{\text {SEC }}$ (PS-Precursor) or to the presence of inter-chain aggregates in the samples leading to $R_{H}^{\text {DLS }}$ (PS-SCNP) $>R_{H}^{\text {SEC }}$ (PS-Precursor). In general, a good agreement is found between $R_{H}{ }^{\text {SEC }}$ and $R_{H}{ }^{\text {DLS }}$ data, as illustrated in Fig. 2a for PS-SCNPs synthesized from linear precursors having $20 \mathrm{~mol} \%$ of reactive functional groups. Last columns in Table 1 provide the hydrodynamic radii for compact and partially swollen PS globules with a $M_{w}$ value identical to that of the SCNP precursor according to the expression: ${ }^{26} R_{H}{ }^{\phi}=$ $\left[3 M_{w} /\left(4 \pi \phi \rho N_{A}\right)\right]^{1 / 3}$, where $\phi$ is the segment volume fraction in the globule ( $\phi=1$ for solid-like globules; $\phi=0.8$ for partially swollen globules with $20 \%$ solvent content), $\rho$ is the density of PS $\left(1.05 \mathrm{~g} / \mathrm{cm}^{3}\right)$ and $N_{A}$ is Avogadro's number.

Inspection of data compiled in Table 1 allows one to conclude that the hydrodynamic radius of a PS-SCNP is, in general, larger than that of a compact or partially swollen PS globule of the same molecular weight, independently of the 
Table 1. Size data for polystyrene single-chain nanoparticles (PS-SCNPs) synthesized from different precursors and intrachain cross-linking chemistries compared to the predicted size data for compact and partially swollen PS globules.

\begin{tabular}{|c|c|c|c|c|c|c|c|c|c|c|c|}
\hline & \multicolumn{4}{|c|}{ Precursors } & \multicolumn{5}{|c|}{ SCNPs } & \multicolumn{2}{|c|}{ Globules } \\
\hline$\#$ & $\begin{array}{c}x \\
(\mathbf{m o l} \\
\%)^{\mathrm{a}} \\
\end{array}$ & $\begin{array}{c}M_{w} \\
(\mathbf{k D a})^{b}\end{array}$ & $\boldsymbol{D}^{\mathbf{c}}$ & $\begin{array}{l}R_{H}^{\text {SEC }} \\
(\mathbf{n m})^{\mathrm{d}}\end{array}$ & Type $^{\mathrm{e}}$ & $\begin{array}{l}\text { Crosslinking } \\
\text { Chemistry }\end{array}$ & $\begin{array}{l}\text { SCNP } \\
M_{w}{ }^{a p p} \\
(\mathrm{kDa})^{\mathrm{f}}\end{array}$ & $\begin{array}{l}R_{H}^{\text {SEC }} \\
(\mathbf{n m})^{\mathrm{d}}\end{array}$ & $\begin{array}{l}R_{H}^{\text {DLS }} \\
(\mathrm{nm})^{\mathrm{g}}\end{array}$ & $\begin{array}{l}R_{H}^{\phi=1} \\
(\mathrm{~nm})^{\mathrm{h}}\end{array}$ & $\begin{array}{c}R_{H}^{\phi=0.8} \\
(\mathrm{~nm})^{\mathrm{i}}\end{array}$ \\
\hline 1 & 10 & 172.8 & 1.60 & 12.5 & \multirow[t]{2}{*}{$\mathrm{CBs}$} & \multirow{2}{*}{$\begin{array}{l}\text { Radical cou- } \\
\text { pling }^{13}\end{array}$} & 70.5 & 7.6 & 9.2 & 4.0 & 4.3 \\
\hline 2 & 16 & 41.3 & 1.29 & 5.6 & & & 18.0 & 3.5 & 5.4 & 2.5 & 2.7 \\
\hline 3 & 10 & 112.0 & 1.10 & 9.8 & \multirow[t]{9}{*}{$\mathrm{CBs}$} & \multirow{9}{*}{$\begin{array}{c}\text { Benzo- } \\
\text { cyclobutene } \\
\text { dimerization }^{14}\end{array}$} & 56.0 & 6.6 & 6.2 & 3.5 & 3.8 \\
\hline 4 & 10 & 233.0 & 1.26 & 14.8 & & & 91.5 & 8.7 & 9.5 & 4.4 & 4.8 \\
\hline 5 & 15 & 110.0 & 1.16 & 9.7 & & & 42.2 & 5.7 & - & 3.5 & 3.7 \\
\hline 6 & 15 & 235.0 & 1.23 & 14.8 & & & 80.3 & 8.1 & - & 4.4 & 4.8 \\
\hline 7 & 20 & 44.0 & 1.07 & 5.8 & & & 18.5 & 3.6 & - & 2.4 & 2.6 \\
\hline 8 & 20 & 85.0 & 1.14 & 8.4 & & & 34.0 & 5.0 & - & 3.0 & 3.3 \\
\hline 9 & 20 & 111.0 & 1.15 & 9.7 & & & 42.8 & 5.7 & - & 3.3 & 3.6 \\
\hline 10 & 20 & 230.0 & 1.21 & 14.7 & & & 66.0 & 7.3 & - & 4.2 & 4.6 \\
\hline 11 & 25 & 229.0 & 1.25 & 14.6 & & & 62.0 & 7.0 & 6.4 & 4.4 & 4.8 \\
\hline 12 & 10 & 38.0 & 1.07 & 5.3 & \multirow[t]{2}{*}{$\mathrm{CBs}$} & \multirow{2}{*}{$\begin{array}{l}\text { Isocyanate-amine } \\
\text { coupling }^{15}\end{array}$} & 14.0 & 3.1 & $4.4^{j}$ & 2.4 & 2.6 \\
\hline 13 & 10 & 72.0 & 1.19 & 7.6 & & & 50.5 & 6.3 & $5.9^{j}$ & 3.0 & 3.2 \\
\hline 14 & 15 & 118.8 & 1.20 & 10.1 & CBs & $\begin{array}{l}\text { CuAAC }^{\mathrm{k}} \text { click } \\
\text { chemistry }^{16}\end{array}$ & 76.5 & 7.9 & 5.0 & 3.3 & 3.6 \\
\hline 15 & 15 & 46.9 & 1.54 & 6.0 & \multirow[t]{2}{*}{$\mathrm{CBs}$} & \multirow{2}{*}{$\begin{array}{c}\text { Nitrene } \\
\text { chemistry }^{17}\end{array}$} & 24.9 & 4.2 & $(8.0)$ & 2.6 & 2.8 \\
\hline 16 & 20 & 47.1 & 1.46 & 6.0 & & & 20.6 & 3.8 & $(7.5)$ & 2.6 & 2.8 \\
\hline 17 & 10 & 39.2 & 1.37 & 5.4 & \multirow[t]{6}{*}{$\mathrm{CBs}$} & \multirow{6}{*}{$\begin{array}{l}\text { Benzoxazine } \\
\text { chemistry }^{18}\end{array}$} & 24.8 & 4.2 & $(6.1)$ & 2.5 & 2.6 \\
\hline 18 & 10 & 147.9 & 1.62 & 11.4 & & & 67.0 & 7.3 & 10.6 & 3.8 & 4.1 \\
\hline 19 & 15 & 42.8 & 1.33 & 5.7 & & & 22.7 & 4.0 & 5.7 & 2.5 & 2.7 \\
\hline 20 & 15 & 79.1 & 1.31 & 8.1 & & & 29.5 & 4.6 & 7.1 & 3.1 & 3.3 \\
\hline 21 & 20 & 56.2 & 1.46 & 6.7 & & & 23.5 & 4.1 & 5.1 & 2.8 & 3.3 \\
\hline 22 & 20 & 95.6 & 1.48 & 9.0 & & & 31.5 & 4.8 & 6.8 & 3.3 & 3.6 \\
\hline 23 & 19 & 57.1 & 1.18 & 6.7 & $\mathrm{CBs}$ & $\begin{array}{l}\text { Glaser-Hay } \\
\text { Coupling }^{19}\end{array}$ & 25.1 & 4.2 & 5.5 & 2.8 & 3.0 \\
\hline 24 & 9 & 18.4 & 1.22 & $4.5^{1}$ & \multirow[t]{3}{*}{ CBs } & \multirow{3}{*}{$\begin{array}{l}\text { Diels/Alder } \\
\text { ligation }^{20}\end{array}$} & 13.6 & 3.0 & 3.5 & 1.9 & 2.1 \\
\hline 25 & 17 & 22.1 & 1.33 & $4.0^{1}$ & & & 15.9 & 3.3 & 2.5 & 2.0 & 2.2 \\
\hline 26 & 34 & 31.5 & 1.56 & $4.0^{1}$ & & & 21.7 & 3.9 & $(0.8)^{\mathrm{m}}$ & 2.3 & 2.5 \\
\hline 27 & 20 & 45.8 & 1.83 & 5.9 & CBs & $\begin{array}{l}\text { Tetrazine- } \\
\text { norbornene } \\
\text { chemistry }^{21}\end{array}$ & 16.3 & 3.3 & 3.7 & 2.6 & 2.8 \\
\hline 28 & 21 & 17.3 & 1.27 & $2.7^{1}$ & DCBs & $\begin{array}{l}\text { Hydrazone } \\
\text { chemistry }^{22}\end{array}$ & 10.7 & 2.6 & $(2.8)$ & 1.9 & 2.0 \\
\hline 29 & 9 & 27.6 & 1.17 & $4.8^{1}$ & \multirow[t]{2}{*}{ NCBs } & \multirow{2}{*}{$\begin{array}{c}\text { Ureido- } \\
\text { pyrimidinone } \\
\text { dimerization }^{23}\end{array}$} & 22.5 & 4.0 & 4.4 & 2.2 & 2.4 \\
\hline 30 & 9 & 33.6 & 1.17 & $6.3^{1}$ & & & 28.4 & 4.5 & 5.7 & 2.3 & 2.5 \\
\hline
\end{tabular}

\footnotetext{
${ }^{a}$ Relative amount of functional groups in the PS linear precursor. ${ }^{b}$ Weight average molecular weight referred to PS standards. ${ }^{c}$ Dispersity of the molecular weight distribution referred to PS standards. ${ }^{\mathrm{d}}$ For the PS polymer precursors: $R_{H}^{\mathrm{SEC}}(\mathrm{nm})=1.44 \times 10^{-2} M_{w}^{0.561}$ (see ref 24); for the PS-SCNPs: $R_{H}^{\mathrm{SEC}}(\mathrm{nm})=1.44 \times 10^{-2}\left(M_{w}^{a p p}\right)^{0.561} .{ }^{\mathrm{e}} \mathrm{CBs}=$ Covalent bonds. DCBs $=$ Dynamic covalent bonds. NCBs $=$ Non-covalent bonds. ${ }^{\mathrm{f}} M_{w}{ }^{a p p}$ is the apparent weight average molecular weight of the SCNP referred to PS standards (see ref 25). ${ }^{\mathrm{g}}$ Data from dynamic light scattering (DLS) measurements. In parentheses: data in which $R_{H}{ }^{\mathrm{DLS}}(\mathrm{SCNP})>R_{H}{ }^{\mathrm{SEC}}$ (Precursor). ${ }^{\mathrm{h}}$ Compact PS globules: $R_{H}{ }^{\phi=1}=$ $\left[3 M_{w} /\left(4 \pi \phi \rho \mathrm{N}_{\mathrm{A}}\right)\right]^{1 / 3}$ with $\phi=1$ and $\rho=1.05 \mathrm{~g} / \mathrm{cm}^{3} . \mathrm{N}_{\mathrm{A}}$ is Avogadro's number (see ref 26). ${ }^{\mathrm{i}}$ Partially swollen PS globules (solvent content: 20\%): $R_{H}{ }^{\phi=0.8}=\left[3 M_{w} J\left(4 \pi \phi \rho \mathrm{N}_{\mathrm{A}}\right)\right]^{1 / 3}$ with $\phi=0.8 .{ }^{\mathrm{j}}$ Chloroform as solvent. ${ }^{\mathrm{k}} \mathrm{CuAAC}=\mathrm{Copper}(\mathrm{I})$-catalyzed azide alkyne cycloaddition. ${ }^{1}$ Experimental value of the hydrodynamic radius from DLS experiments in THF. ${ }^{\mathrm{m}}$ Shown in parentheses because $R_{H}{ }^{\mathrm{DLS}}(\mathrm{SCNP})<R_{H}{ }^{\phi=1}$.
} 
(a)

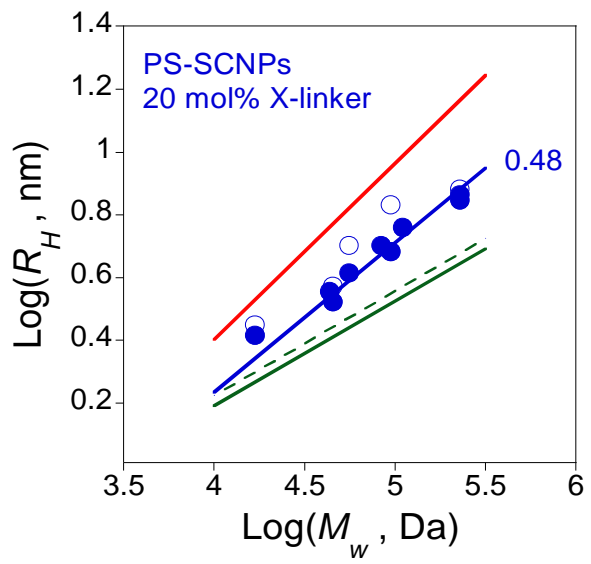

(b)

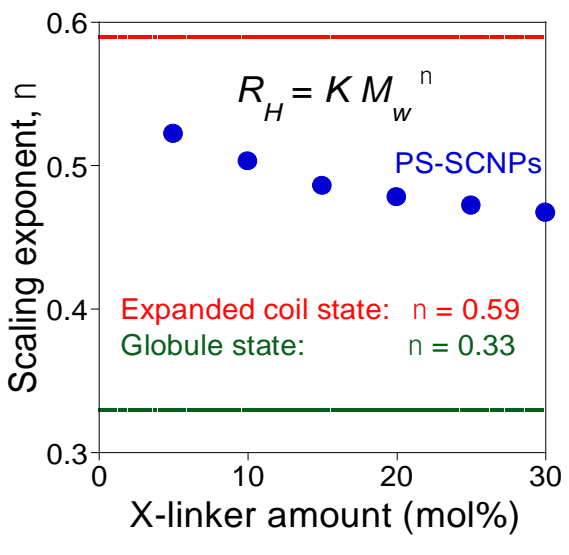

(c)

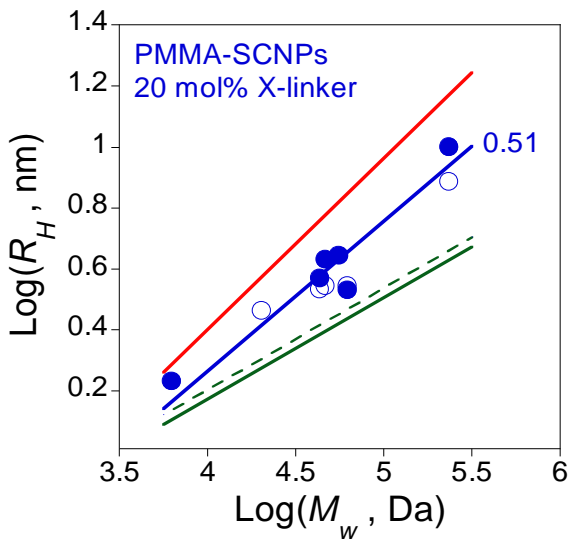

Figure 2. (a) Illustration of the $R_{H}{ }^{\mathrm{SEC}}=K M_{w}{ }^{v}$ scaling law for PS-SCNPs synthesized from PS precursors containing $20 \mathrm{~mol} \%$ of reactive functional groups (closed circles). Open circles are $R_{H}$ data from DLS measurements $\left(R_{H}{ }^{\text {DLS }}\right)$. The blue line is a fit (giving $\left.v=0.48\right)$ of the SEC data. The red line corresponds to the linear precursor; the solid and dashed green lines correspond to compact and partially swollen globules, respectively. (b) The value of the exponent $v$ in the $R_{H}{ }^{\mathrm{SEC}}=K M_{w}{ }^{v}$ scaling law for PS-SCNPs decreases upon increasing the amount of reactive cross-linker (X-linker) functional groups in the precursor. The expected values of the $v$ exponent for expanded coils and globules are illustrated by the red and green lines, respectively. A plateau is observed at high amount of functional groups in the precursor. (c) As panel (a), for PMMA-SCNPs synthesized from PMMA precursors containing $20 \mathrm{~mol} \%$ of reactive functional groups.

intrachain cross-linking chemistry used to synthesize the PSSCNP. More insight is obtained by analyzing the PS-SCNP size data in terms of the power-law relation $R_{H} \propto M_{w}{ }^{v}$. It is well-known that for linear polymers the specific value of $v$ depends on the particular state of the chain, with a value $c a$. $v_{\mathrm{F}}=0.59$ (Flory exponent) for the expanded coil state (i.e., chain in good solvent), $1 / 2$ for the $\Theta$-state and $1 / 3$ for the most compact globule state. ${ }^{27}$ As illustrated in Fig. $2 b$, the value of the exponent $v$ for the PS-SCNPs decreases progressively, upon increasing the amount of reactive cross-linker (X-linker) functional groups in the PS precursor, to a limiting value of $v$ $\approx 0.47$, which is close to that of the $\Theta$-state and far from the value of 0.33 expected for compact globules. The presence of a plateau in Fig. $2 \mathrm{~b}$ above $30 \mathrm{~mol} \%$ of X-linker in the precursor means that a further increase in X-linker content is not expected to be efficient for compaction. This feature is in agreement with MD simulations (see below). ${ }^{9}$ Figure $2 \mathrm{c}$ shows similar results to those of Figure 2a, for poly(methyl methacrylate) single-chain nanoparticles (PMMA-SCNPs) in solution synthesized from linear precursors having $20 \mathrm{~mol} \%$ of reactive functional groups (see Table $\mathrm{S} 1$ ). A good agreement is again observed between $R_{H}^{\text {SEC }}$ and $R_{H}^{\text {DLS }}$ data. Fitting the data to $R_{H}$ $\propto M_{w}{ }^{v}$, a value $v=0.51$ is obtained, consistent within experimental error (ca. $4 \%$ ) with the value $v=0.48$ found for PSSCNPs. For comparison, the values of $v$ reported for chemically denatured, intrinsically disordered, and folded proteins are $0.57,0.51$ and 0.29 , respectively. ${ }^{28,29}$ Thus, chemically denatured proteins behave as expanded coils in solution $(v \approx$ 0.59 ), whereas folded proteins follow the scaling law expected for compact globules $(v \approx 0.33)$. The values obtained in Figures $2 \mathrm{a}$ and $2 \mathrm{c}$ for the exponent $v$ for PS-SCNPs and PMMASCNPs are within statistics consistent with those of linear chains in the $\Theta$-state, or intrinsically disordered proteins in solution $(v \approx 0.5)$. Our group recently reported the similarity in the SANS form factor of SCNPs in solution to that of IDPs showing locally compact structures connected by flexible chain segments. ${ }^{6}$

SCNPs based on PMMA and PS precursors are the systems with the largest collection of data available in the literature (Tables 1 and S1). Though many other SCNPs have been characterized (Table S2), data sets for each individual system are limited in most cases, and fits of such sets to an scaling law $R_{H} \propto M_{w}{ }^{\nu}$ are not reliable. However, the whole set of data ${ }^{13-23,30-50}$ in Tables $1, \mathrm{~S} 1$ and $\mathrm{S} 2$ can be used for deriving a qualitative universal trend of the scaling behavior of the SCNPs. Figure 3 shows all data for $R_{H}$ of the SCNPs vs. the data of the respective precursors. Since the polymer precursors must scale as $R_{H \text { prec }} \propto M_{w}{ }^{{ }}$F (ideal chains in good solvent, with $v_{\mathrm{F}}=0.59$ ), the size of the SCNP (scaling with some exponent $v)$ can be related to the size of the precursor as $R_{H \text { nanop }}=$ $a\left[R_{H \text { prec }}\right]^{v / v_{\mathrm{F}}}$. The prefactor $a$ is of the order of 1 (irrelevant within the statistics of Figure 3), since the statistical segments of the precursor and SCNP must be very similar in size.

Though small corrections are expected for each SCNP (e.g., related to the amount of X-linkers as discussed above), the representation of Figure 3 provides information about the average value of the scaling exponent $v$. The best fit of the global SEC data to the expression $R_{H \text { nanop }}=a\left[R_{\mathrm{H} \text { prec }}\right]^{v / v_{\mathrm{F}}}$ yields an exponent $v=0.48$, consistent with the values obtained from the specific analysis of PS-SCNPs and PMMASCNPs with $20 \%$ of X-linkers (Figs. 2a and 2c). For comparison, we include in Figure 3 the case of no reduction respect to the precursor $\left(\mathrm{v}=\mathrm{v}_{\mathrm{F}}=0.59\right.$ and $\mathrm{a}=1$, leading to $R_{H \text { nanop }}=$ 
$R_{H \text { prec }}$; green line), and the case of compact globular SCNPs ( $v=1 / 3$ with $\phi=1$; blue line).
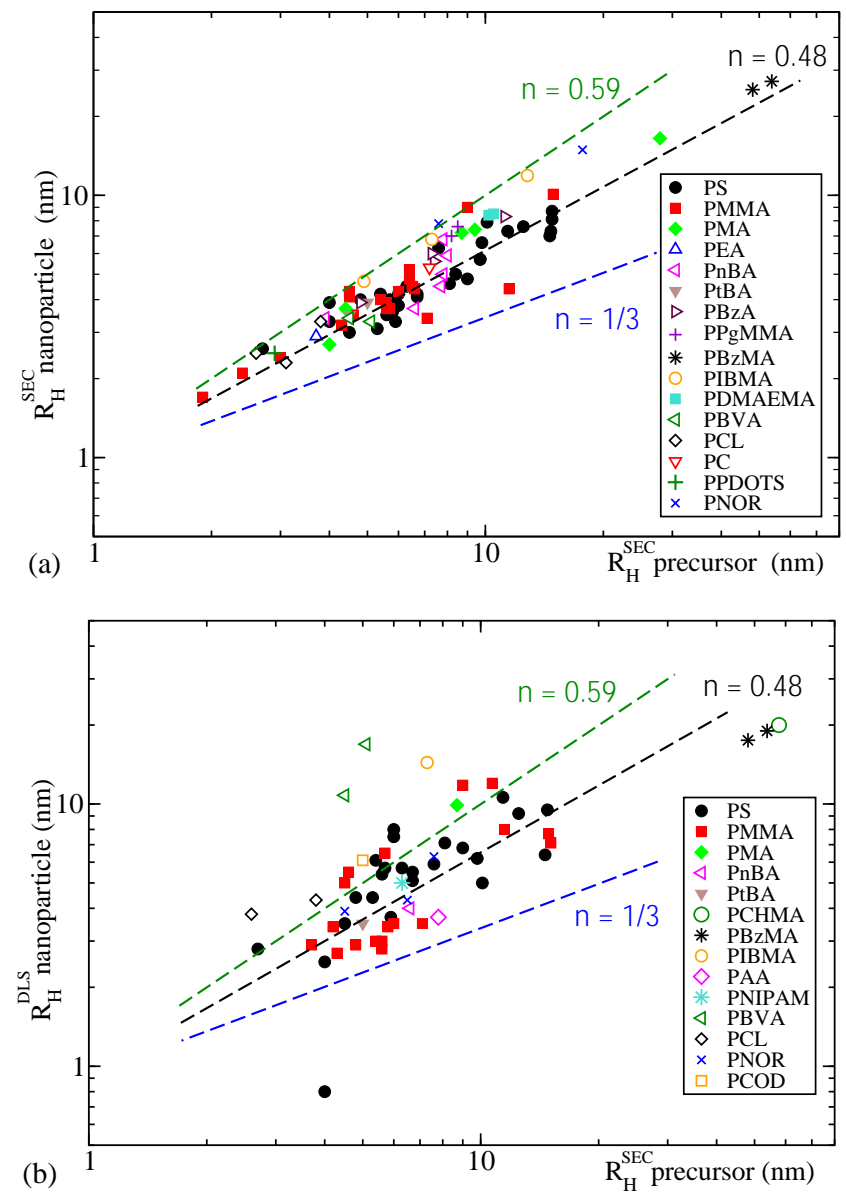

Figure 3. Illustration of hydrodynamic radii reported in the literature $^{13-23,30-50}$ for SCNPs and their precursors. All numerical values are given in the Tables 1, S1 and S2. In both panels abscisas are the values obtained for the precursors by SEC. Ordinates are the respective values for the nanoparticles obtained by SEC (a) and DLS (b). Data for different systems are represented with different symbols (see legends). Dashed lines correspond to scaling behavior $R_{H \text { nanop }}^{\mathrm{SEC} / \mathrm{DLS}}=a\left[R_{H \mathrm{prec}}^{\mathrm{SEC}}\right]^{v / \nu_{\mathrm{F}}}$ (see text for explanation). In this expression $a$ is a prefactor, $v_{\mathrm{F}}=0.59$ is the Flory exponent for chains in good solvent (i.e., for the precursors), and $v$ is the scaling exponent for the nanoparticle. The blue line $(v=1 / 3)$ corresponds to globular nanoparticles with $\phi=1$. The black line is the

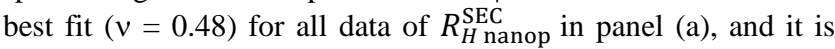
included in (b) for comparison. The green line corresponds to $v=v_{\mathrm{F}}=0.59$ and $a=1$, i.e, it indicates the hypothetical case of no reduction of the nanoparticle size respect to the precursor $\left(R_{H \text { nanop }}=R_{H \text { prec }}\right)$.

From the analysis of the data in Figure 3, a global picture emerges for the current SCNPs in solution: they do not display a compact, globular morphology. Instead they show within statistics the behavior expected for chains in $\Theta$-solvent or for intrinsically disordered proteins, confirming the physical picture proposed by recent scattering experiments and MD simulations ${ }^{6-10}$. The simulations reveal that, because of the intrinsi- cally self-avoiding character of the polymer precursors in good solvent, reaction between X-linkers separated by long contour distances (creating long-range loops) is severely restricted. Therefore, most of the cross-linking events are actually inefficient for global compaction, since they involve X-linkers that are separated by short contour distances. Indeed for this reason, increasing the amount of $\mathrm{X}$-linkers in the precursor does not significantly improve the efficiency of folding into compact structures (Figure 2b). This mostly leads to an increase of the short-range cross-linking events, which just produce local globulation (resembling the behavior of chains in $\Theta$-solvents or IDPs), but at large scales SCNPs are open, sparse objects showing just a few amount of long-range loops (Figure 1b).

The summary of literature results presented in this Viewpoint provides a global picture for the conformational properties of current SCNPs produced by state-of-art methods. The analysis reveals that they adopt open, sparse morphologies resembling those of intrinsically disordered proteins, instead of globular conformations. Even if this can be considered as a major step towards protein-like soft nanoparticles, new synthesis routes need to be developed to produce SCNPs with well-defined compact morphologies. By taking inspiration from globular proteins in which multiple (e.g., van der Wals, hydrophobic, hydrogen bonding, ionic) interactions are cooperatively involved allowing protein solubility, a similar strategy should be implemented for the synthesis of true SCNP globules in solution. Recent work in synthetic polypeptoids has revealed the importance of hydrophobic sequence patterning on the coil-to-globule transition for these protein-like polymers lacking backbone hydrogen bonding and chirality when compared to natural polypeptides. ${ }^{51}$ Additionally, the critical role of ionic interactions during the self-assembly of water insoluble polymers into stable spheroidal SCNPs in aqueous medium has been recently demonstrated. ${ }^{52}$ Precision synthesis of precursors with predefined sequences, ${ }^{1,5}$ positionable X-linkers ${ }^{53}$ and tailored interactions ${ }^{54}$ seems to be the key, among other approaches, to access the true globule limit of SCNPs in solution.

\section{ASSOCIATED CONTENT}

Comparison of size data for PMMA-SCNPs and other SCNPs of different chemical structure with size data of compact and swollen globules of the same molecular weight. This material is available free of charge via the Internet at http://pubs.acs.org.

\section{AUTHOR INFORMATION}

\section{Corresponding Author}

*E-mail: josetxo.pomposo@ehu.es

\section{Notes}

The authors declare no competing financial interest.

\section{ACKNOWLEDGMENT}

Financial support from the Projects MAT2012-31088 (MINECO), T-65413 (GV) and S-PE13UN034 (GV) is acknowledged. I. P.-B. acknowledges CSIC for her JAE-PREDOC grant. This work is based on experiments performed at the Swiss spallation neutron source SINQ, Paul Scherrer 
Institute, Villigen, Switzerland, and has been supported by the European Commission under the $7^{\text {th }}$ Framework Programme through the "Research Infrastructures" action of the "Capacities" Programme, NMI3-II Grant Number 283883. We acknowledge CSUC (Spain) for generous allocation of CPU time.

\section{ABBREVIATIONS}

PMA = Poly(methyl acrylate), PEA = Poly(ethyl acrylate), PnBA = Poly (n-butyl acrylate), PtBA = Poly( $t$-butyl acrylate $), \operatorname{PBzA}=$ Poly(benzyl acrylate), PPgMMA = Poly (propargyl methacrylate / methyl methacrylate $)$ PCHMA = Poly (cyclohexyl methacrylate $),$ PBzMA = Poly(benzyl methacrylate), PIBMA = Poly(isobornyl methacrylate), PDMAEMA = $\operatorname{Poly}(N, N$-dimethylaminoethyl methacrylate), PAA = Poly(acrylic acid), PNIPAM = Poly $(N$-isopropyl acrylamide $), \operatorname{PBVA}=\operatorname{Poly}(4-N-$ Boc vinylaniline), $\mathrm{PCL}=\operatorname{Poly}(\varepsilon$-caprolactone $), \quad \mathrm{PC}=$ Poly (carbonate), PPDOTS $=$ Poly(3,4-propylenedioxythiophene bearing styrene), PNOR = Poly(norbornene), PCOD = Poly(1,5-cyclooctadiene).

\section{REFERENCES}

(1) Ouchi, M.; Badi, N.; Lutz, J.-F.; Sawamoto, M. Nat. Chem. 2011, $3,917-924$.

(2) Altintas, O.; Barner-Kowollik, C. Macromol. Rapid Commun. 2012, 33, 958-971.

(3) Sanchez-Sanchez, A.; Pomposo, J. A. Part. Part. Syst. Charact. 2014, 31, 11-23.

(4) Sanchez-Sanchez, A.; Perez-Baena, I.; Pomposo, J. A. Molecules 2013, 18, 3339-3355.

(5) Lutz, J.-F.; Ouchi, M.; Liu, D. R.; Sawamoto, M. Science 2013, 341, 1238149.

(6) Sanchez-Sanchez, A.; Akbari, S.; Etxeberria, A.; Arbe, A.; Gasser, U.; Moreno, A. J.; Colmenero, J.; Pomposo, J. A. ACS Macro Lett. 2013, 2, 491-495.

(7) Perez-Baena, I.; Barroso-Bujans, F.; Gasser, U.; Arbe, A.; Moreno, A. J.; Colmenero, J.; Pomposo, J. A. ACS Macro Lett. 2013, 2, 775-779.

(8) Sanchez-Sanchez, A.; Akbari, S.; Moreno, A. J.; Lo Verso, F.; Arbe, A.; Colmenero, J.; J. A. Pomposo, Macromol. Rapid Commun. 2013, 34, 1681-1686.

(9) Moreno, A. J.; Lo Verso, F.; Sanchez-Sanchez, A.; Arbe, A.; Colmenero, J.; Pomposo, J. A. Macromolecules 2013, 46, 9748-9759.

(10) Lo Verso, F.; Pomposo, J. A.; Colmenero, J.; Moreno, A. J. Soft Matter 2014, 10, 4813-4821.

(11) Receveur-Bréchot, V.; Durand, D. Curr. Protein Pept. Sci. 2012 13, 55-75.

(12) Stals, P. J. M.; Gillissen, M. A. J.; Paffen, T. F. E.; de Greef, T. F. A.; Lindner, P.; Meijer, E. W.; Palmans, A. R. A.; Voets, I. K. Macromolecules 2014, 47, 2947-2954.

(13) Mecerreyes, D.; Lee, V.; Hawker, C. J.; Hedrick, J. L.; Wursch, A.; Volksen, W.; Magbitang, T.; Huang, E.; Miller, R. D. Adv. Mater. 2001, 13, 204-208.

(14) Harth, E.; Horn, B. V.; Lee, V. Y.; Germack, D. S.; Gonzales, C. P.; Miller, R. D.; Hawker, C. J. J. Am. Chem. Soc. 2002, 124, 86538660 .

(15) Beck, J. B.; Killops, K. L.; Kang, T.; Sivanandan, K.; Bayles, A.; Mackay, M. E.; Wooley, K.; Hawker, C. J. Macromolecules 2009, 42, 5629-5635.

(16) Ruiz de Luzuriaga, A.; Perez-Baena, I.; Montes, S.; Loinaz, I.; Odriozola, I.; García, I.; Pomposo, J. A. Macromol. Symp. 2010, 296, 303-310.

(17) Jiang, X.; Pu, H.; Wang, P. Polymer 2011, 52, 3597-3602.
(18) Wang, P.; Pu, H.; Jin, M. J. Polym. Sci., Pol. Chem. 2011, 49, 5133-5141.

(19) Khanjani, P.; Perez-Baena, I.; Buruaga, L.; Pomposo, J. A. Macromol. Symp. 2012, 321-322, 145-149.

(20) Altintas, O.; Willenbacher, J.; Wuest, K. N. R.; Oehlenschlaeger, K. K.; Krolla-Sidenstein, P.; Gliemann, H.; Barner-Kowollik, C. Macromolecules 2013, 46, 8092-8101.

(21) Hansell, C. F.; Lu, A.; Patterson, J. P.; O’Reilly, R. K. Nanoscale 2014, 6, 4102-4107.

(22) Murray, B. S.; Fulton, D. A. Macromolecules 2011, 44, 72427252 .

(23) Stals, P. J. M.; Gillissen, M. A. J.; Nicolaÿ, R.; Palmans, A. R. A.; Meijer, E. W. Polym. Chem. 2013, 4, 2584-2597.

(24) Fetters, L. J.; Hadjichristidis, N.; Lindner, J. S.; Mays, J. W. J. Phys. Chem. Ref. Data 1994, 23, 619-640.

(25) Pomposo, J. A.; Perez-Baena, I.; Buruaga, L.; Alegría, A.; Moreno, A. J.; Colmenero, J. Macromolecules 2011, 44, 8644-8649.

(26) Gürel, E. E.; Kayaman, N.; Baysal, B. M.; Karasz, F. E. J. Polym. Sci., Pol. Phys. 1999, 37, 2253-2260.

(27) Rubinstein, M.; Colby, R. H. Polymer Physics; Oxford University Press, Inc.: New York, 2003.

(28) Wilkins, D. K.; Grimshaw, S. B.; Receveur, V.; Dobson, C. M.; Jones, J. A.; Smith, L.J. Biochemistry 1999, 38, 16424-16431.

(29) Marsh, J. A.; Forman-Kay, J. D. Biophys. J. 2010, 98, $2383-$ 2390 .

(30) Ruiz de Luzuriaga, A.; Ormategui, N.; Grande, H. J.; Odriozola, I.; Pomposo, J. A.; Loinaz, I. Macromol. Rapid Commun. 2008, 29, 1156-1160

(31) Zhu, B.; Ma, J.; Li, Z.; Hou, J.; Cheng, X.; Quian, G.; Liu, P.; Hu, A. J. Mater. Chem. 2011, 21, 2679-2683.

(32) Sanchez-Sanchez, A.; Asenjo-Sanz, I.; Buruaga, L.; Pomposo, J. A. Macromol. Rapid Commun. 2012, 33, 1262-1267.

(33) Frank, P. G.; Tuten, B. T.; Prasher, A.; Chao, D.; Berda, E. B. Macromol. Rapid Commun. 2014, 35, 249-253.

(34) Sanchez-Sanchez, A.; Fulton, D. A.; Pomposo, J. A. Chem. Commun. 2014, 50, 1871-1874

(35) Seo, M.; Beck, B. J.; Paulusse, J. M. J.; Hawker, C. J.; Kim, S. Y. Macromolecules 2008, 41, 6413-6418.

(36) Zhu, B.; Qian, G.; Xiao, Y.; Deng, S.; Wang, M.; Hu, A. J. Polym. Sci., Pol. Chem. 2011, 49, 5330-5338.

(37) Zhu, B.; Sun, S.; Wang, Y.; Deng, S.; Qian, G.; Wang, M.; Hu, A. J. Mater. Chem. C 2013, 1, 580-586.

(38) Croce, T. A.; Hamilton, S. K.; Chen, M. L.; Muchalski, H.; Harth, E. Macromolecules 2007, 40, 6028-6031.

(39) Qian, G.; Zhu, B.; Wang, Y.; Deng, S.; Hu, A. Macromol. Rapid Commun. 2012, 33, 1393-1395.

(40) Berda, E. B.; Foster, J.; Meijer, E. W. Macromolecules 2010, 43, 1430-1437.

(41) Hosono, N.; Gillisen, M. A.; Li, Y.; Sheiko, S. S.; Palmans, A. R. A.; Meijer, E. W. J. Am. Chem. Soc. 2012, 135, 501-510.

(42) He, J.; Tremblay, L.; Lacelle, S.; Zhao, Y. Soft Matter 2011, 7, 2380-2386.

(43) Dobish, J. N.; Hamilton, S. K.; Harth, E. Polym. Chem. 2012, 3, 857-860.

(44) Jiang, J.; Thayumanavan, S. Macromolecules 2005, 38, 58865891.

(45) Cherian, A. E.; Sun, F. C.; Sheiko, S. S.; Coates, G. W. J. Am. Chem. Soc. 2007, 129, 11350-11351.

(46) Dirlam, P. T.; Kim, H. J.; Arrington, K. J.; Chung, W. J.; Sahoo, R.; Hill, L. J.; Costanzo, P. J.; Theato, P.; Char, K.; Pyun, J. Polym. Chem. 2013, 4, 3765-3773.

(47) Chao, D.; Jia, X.; Tuten, B.; Wang, C.; Berda, E. B. Chem. Commun. 2013, 49, 4178-4180.

(48) Foster, E. J.; Berda, E. B.; Meijer, E. W. J. Am. Chem. Soc. 2009, 131, 6964-6966. 
(49) Tuten, B. T.; Chao, D.; Lyon, C. K.; Berda, E. B. Polym. Chem. 2012, 3, 3068-3071.

(50) Mavila, S.; Diesendruck, C. E.; Linde, S.; Amir, S.; Shikler, R.; Lemcoff, N. G. Angew. Chem. Int. Ed. 2013, 52, 5767-5770.

(51) Murnen, H. K.; Khokhlov, A. R.; Khalatur, P. G.; Segalman, R. A.; Zuckermann, R. N. Macromolecules 2012, 45, 5229-5236.
(52) Riddles, C. J.; Zhao, W.; Hu, H.-J.; Chem, M.; Van De Mark, M. R. Polymer 2014, 55, 48-57.

(53) Shishkan, O.; Zamfir, M.; Gauthier, M. A.; Börnerc, H. G.; Lutz, J.-F. Chem. Commun. 2014, 50, 1570-1572.

(54) Pomposo, J. A. Polym. Int. 2014, 63, 589-592. 


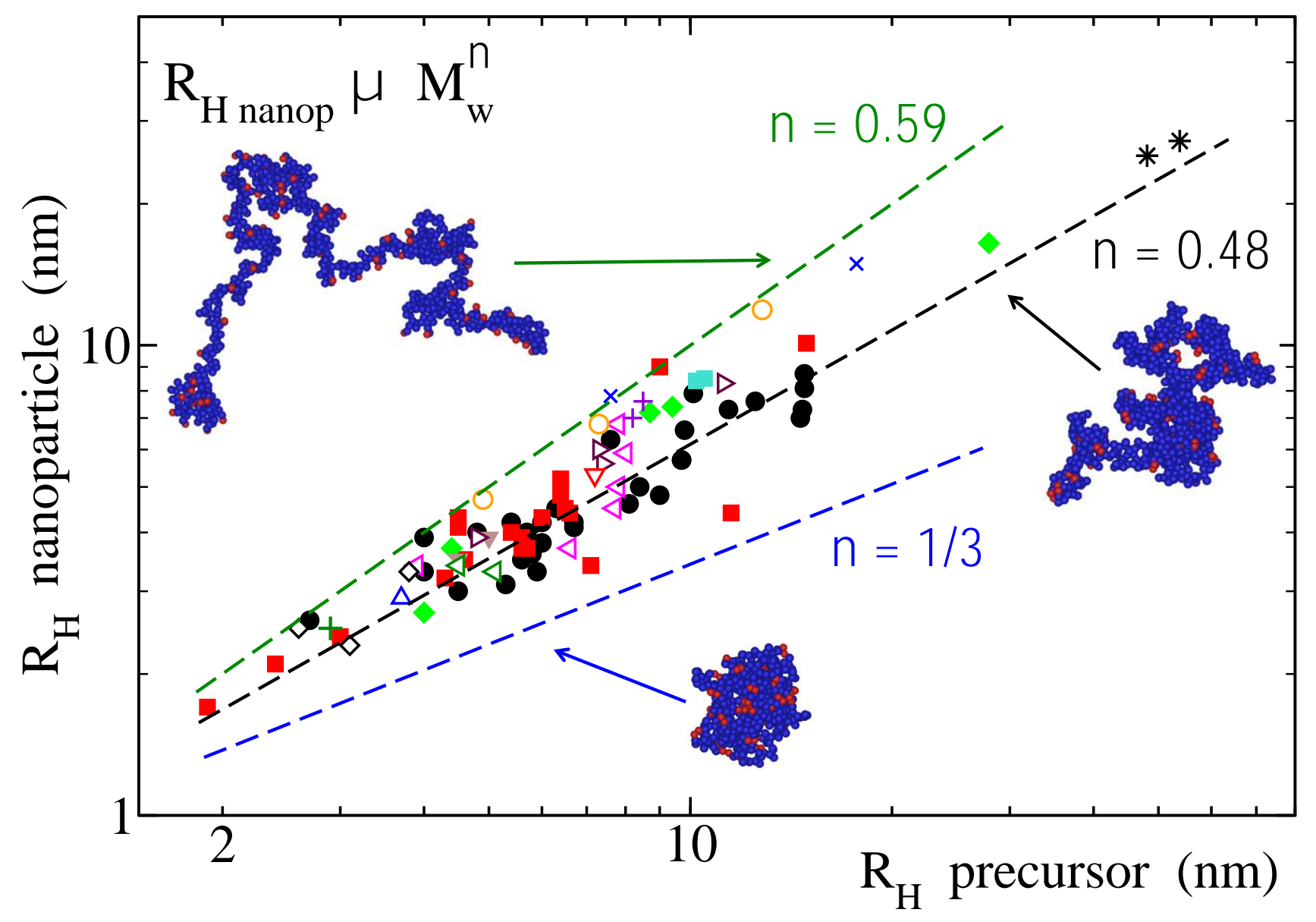

